\title{
Design and simulation of a PV and a PV-Wind standalone energy system: A case study for a household application in Nicosia, Cyprus
}

\author{
Gregoris Panayiotou $^{1,2}$, Soteris Kalogirou ${ }^{1, *}$ and Savvas Tassou ${ }^{2}$ \\ ${ }^{1}$ Department of Mechanical Engineering and Materials Science and Engineering, \\ Cyprus University of Technology, P. O. Box 50329, 3603 Limassol, Cyprus \\ ${ }^{2}$ School of Engineering and Design, Brunel University, Uxbridge, Middlesex UB8 3PH, UK \\ * Tel: +357 25 002621, Fax: +357 25 002637, E-mail: soteris.kalogirou@cut.ac.cy
}

\begin{abstract}
In this work the design and simulation of two stand-alone renewable energy sources (RES) based systems for application in a household in Cyprus is presented. More specifically, the household is located in Nicosia and is used as the residence of a typical Cypriot family for which a baseline scenario of energy consumption is specified in order to define the annual load profile of the house. The first system is based on photovoltaic (PV) modules for the generation of electricity by harvesting the very high solar potential of Cyprus while the second one is a hybrid system combining PVs with a domestic wind turbine in order to take advantage of the wind potential especially during winter. Since both systems are stand alone the energy produced is stored in a battery bank. The software used for the modeling and simulation processes is TRNSYS. A comparison of the two systems in terms of both technical and economical aspects is presented in this study where it is concluded that the wind potential of the specific location of the house, which generally applies on the entire island, cannot substitute and compete in any way with the very high solar potential.
\end{abstract}

Keywords: Stand-alone system, baseline scenario, Cyprus, hybrid, wind potential, solar potential

\section{Baseline Scenario Characteristics}

In order to design the domestic standalone energy systems a typical house is considered for which a baseline scenario concerning several parameters is defined. It is very important to note that the baseline scenario concerns a future situation where all energy for the household is supplied by a RES system and the system is isolated from the grid. The characteristics of the baseline scenario concern the structure, location, occupancy and energy systems installed in the house examined. The data used to define these characteristics were based on the statistical analysis conducted by Panayiotou et al. [1] which concerned the characteristics and the energy behavior of the residential building stock of Cyprus in view of Directive 2002/91/EC.

The house examined in the baseline scenario is a single ground floor house with an area of $160 \mathrm{~m}^{2}$ which was built in year 2000 and is located in Nicosia, Cyprus where the climatic conditions are those for lowland inland Mediterranean areas. The house has 3 bedrooms and it does not have pilotis, sofitta or a basement while it has a flat concrete roof with $140 \mathrm{~m}^{2}$ of free space for any systems such as solar thermal or PVs to be installed. The house has a $5 \mathrm{~cm}$ polyurethane wall insulation and double glazing. The heating and cooling is covered with split type air conditioning units and the number of units installed are two 9,000 BTU $(2.6 \mathrm{~kW})$ in two of three bedrooms and one 12,000 BTU (3.5 kW) unit in the living room. For the production of domestic hot water (DHW) a solar water heating system is used while an immersed electric element is installed for backup.

\section{Typical annual load profile definition}

The typical annual load profile definition was also based on the statistical analysis conducted by Panayiotou et al. [1]. In this statistical analysis a sample of 500 houses along with analytical data given by the Electricity Authority of Cyprus were used and it was concluded that there are two peaks observed on the consumption of electricity in the domestic sector 
annually; one in summer, which is the highest, and one in winter. On the other hand, autumn and spring periods have more or less the same consumption of electricity which is lower compared to that of summer and winter. Also, another very important thing to notice is that the daily average electricity consumption of a house is around $24 \mathrm{kWh}$ during summer, 21 $\mathrm{kWh}$ during winter and $15 \mathrm{kWh}$ during autumn and spring.

To be more precise on the definition of the typical annual load profile this was split into weekdays and weekends for each of the four seasons. The months contained in each season are as follows; Winter: December, January and February; Spring: March, April and May; Summer: June, July and August; and Autumn: September, October and November. Additionally, it should be noted that holiday periods are not considered in the examined typical annual load profile. The typical load profiles for weekdays of spring, autumn and winter are shown in Figs. 1-3 respectively.

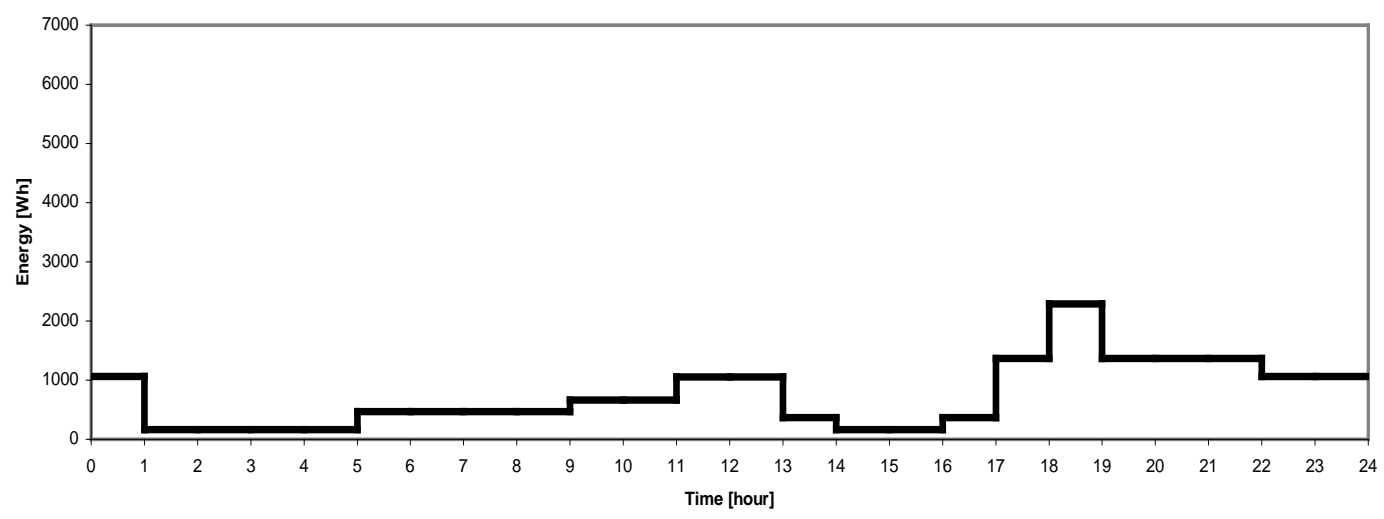

Fig. 1 Load profile for a typical spring/autumn weekday

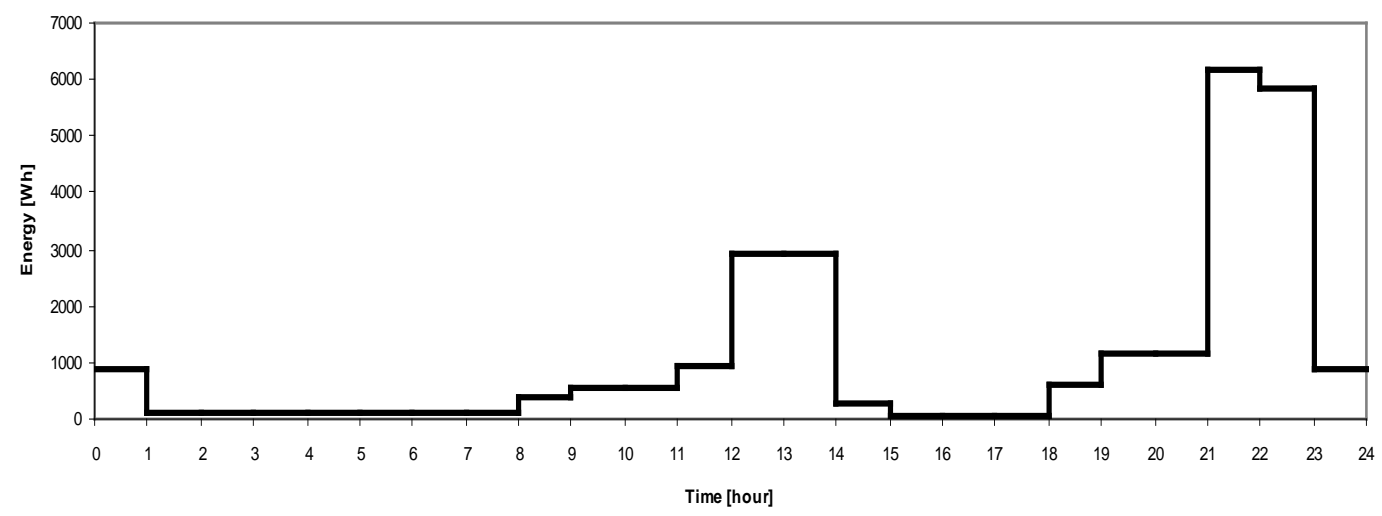

Fig. 2 Load profile for a typical winter weekday

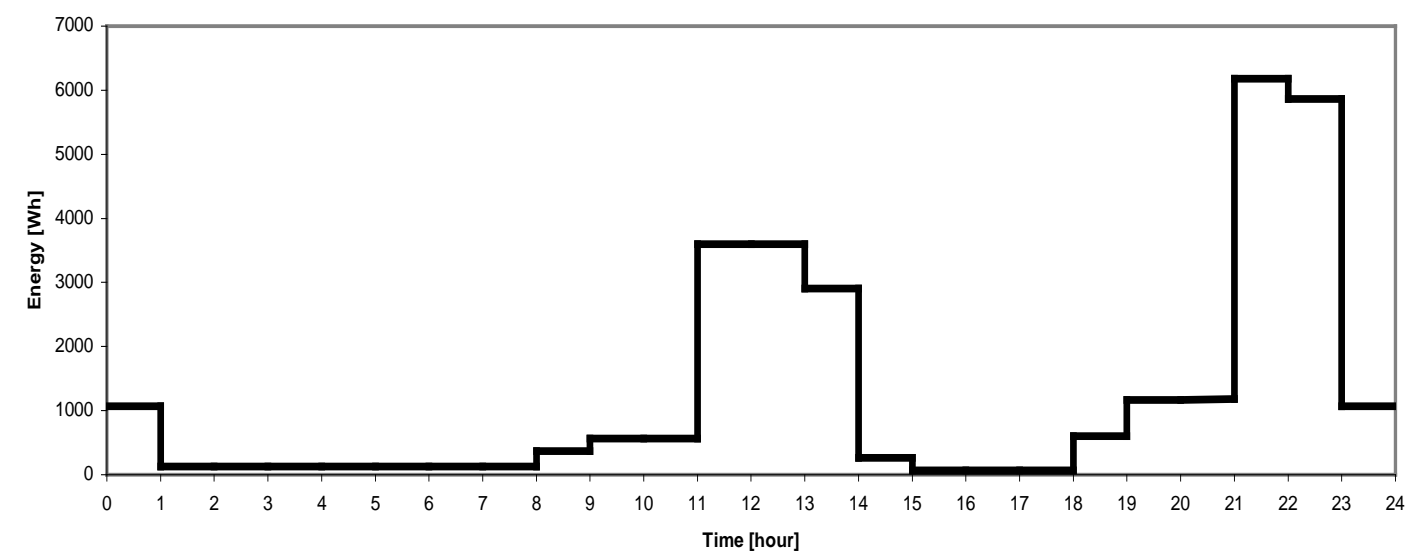

Fig. 3 Load profile for a typical summer weekday 


\section{Model design for standalone PV system}

The model design process was carried out in the TRNSYS environment [2] which is considered to be a complete and extensible simulation environment for the transient simulation of solar and other energy systems.

The model of the standalone PV system includes the following components:

- Weather data processor model (Type 109)

- PV model (Type 180e)

- Inverter/Regulator model (Type 48b)

- Battery model (Type 47a)

- $\quad$ Load Profile model (Type 9a)

A very important parameter to consider when designing a standalone PV system is the nominal voltage of the battery bank which can be 12, 24 or 48 VDC. The parameters affecting the determination of the suitable nominal voltage for a system are the nominal voltage of the PVs, the size of the system and the input requirements of the inverter. For example, inverters which have a power of 6 to $12 \mathrm{~kW}$ require nominal voltage to be $48 \mathrm{~V}$ while inverters with a power of 2 to $5 \mathrm{~kW}$ require the nominal voltage to be $24 \mathrm{~V}$. Since the system examined is neither a large system nor a small one, it was decided that the nominal system voltage is considered initially to be $24 \mathrm{~V}$. The main reason for this decision is that since with a rough estimation the system will not exceed $10-13 \mathrm{~kW}$ of PV power it is much better to use three inverters of $4 \mathrm{~kW}$ instead of one inverter of $10-13 \mathrm{~kW}$ in order to secure basic load coverage in the case of a failure of one inverter.

It is also essential to know the slope of the PVs. A rule of thumb followed by the PV technicians in Cyprus is that the slope of the PVs should be somewhere between 27-31 . In order to define the optimum slope to be used in the modelling process a small model consisting of a typical meteorological year (TMY) and a single PV was developed and a series of simulations were carried out for slopes between $27-33^{\circ}$. The energy production for each slope is recorded and presented in Table 1.

Table 1 PV characteristics on standard testing conditions

\begin{tabular}{cc}
\hline Slope of the PV & Energy Produced $[\mathrm{Wh} / \mathrm{yr}]$ \\
\hline $27^{\circ}$ & 89,516 \\
$28^{\circ}$ & 89,650 \\
$29^{\circ}$ & 89,748 \\
$30^{\circ}$ & 89,810 \\
$31^{\circ}$ & $\mathbf{8 9 , 8 3 5}$ \\
$32^{\circ}$ & 89,823 \\
$33^{\circ}$ & 89,775 \\
\hline
\end{tabular}

According to the results of Table 1 the maximum energy production occurs for a slope of $31^{\circ}$ (shown with bold on Table 1) and thus this is the optimum angle for the location examined and consequently for the island of Cyprus.

\subsection{Simulation and economic analysis of standalone PV system}

After the proper setting up of the complete model for the standalone PV system a series of simulations were carried out in order to specify the required storage capacity and PV array 
power needed to cover the load over the time period of a typical year. Before running the simulations it is essential to decide the acceptable loss of load probability (LOLP) of the specific system which defines the required battery autonomy in days. For example, if a $1 \%$ acceptable LOLP is chosen it means that during the time period of a year there is probability to have 3.65 days where the load will not be covered. Thus, if we want to design a system where we will have a $100 \%$ annual load coverage, in order not to compromise the occupants' quality of living, then a first estimate for the required battery autonomy should be that of 4 days. It should be noted that the batteries capacity must be larger than that calculated for the 4 days of autonomy due to the fact that it is impossible to start the 4 days of autonomy with the batteries fully charged as these always supply electricity to the system during nighttime. Thus, in the system examined, it is predefined that one of the most important parameters to consider for the selection of the PV array size and the required storage capacity is to have $100 \%$ annual load coverage.

Since the nominal voltage of the battery bank is decided to be at $24 \mathrm{~V}$ and the nominal voltage of each battery cell is $2 \mathrm{~V}$ then the configurations of the battery bank used during the simulation consisted of 1, 2, 3 or 4 strings of 12 batteries connected in series.

The results of the simulation process were recorded in a data file and subsequently processed to evaluate the load coverage achieved by each configuration. The most important results estimated during the simulation are presented in Table 2.

Table 2 Results of the simulation process for the standalone PV system

\begin{tabular}{ccccccc}
\hline $\begin{array}{c}\text { Configuration } \\
\text { No }\end{array}$ & $\begin{array}{c}\text { No of } \\
\text { PVs }\end{array}$ & $\begin{array}{c}\text { PV array } \\
\text { power }\end{array}$ & $\begin{array}{c}\text { No of } \\
\text { batteries }\end{array}$ & $\begin{array}{c}\text { Battery } \\
\text { capacity }\end{array}$ & $\begin{array}{c}\text { Annual } \\
\text { energy } \\
\text { deficiency }\end{array}$ & $\begin{array}{c}\text { Annual period } \\
\text { of energy } \\
\text { deficiency }\end{array}$ \\
\cline { 2 - 7 }$[-]$ & {$[\mathrm{kW}]$} & {$[-]$} & {$[\mathrm{kWh}]$} & {$[\mathrm{kWh}]$} & {$[\mathrm{hrs}]$} \\
\hline 1 & 40 & 7.2 & 36 & 108 & 566 & 607 \\
2 & 45 & 8.1 & 36 & 108 & 381 & 451 \\
3 & 50 & 9.0 & 36 & 108 & 228 & 220 \\
4 & 60 & 10.8 & 36 & 108 & 25 & 33 \\
5 & 63 & 11.34 & 36 & 108 & 12 & 2 \\
6 & 65 & 11.7 & 36 & 108 & 2 & 10 \\
7 & 40 & 7.2 & 48 & 144 & 496 & 503 \\
8 & 45 & 8.1 & 48 & 144 & 320 & 365 \\
9 & 50 & 9.0 & 48 & 144 & 193 & 186 \\
10 & 55 & 9.9 & 48 & 144 & 80 & 97 \\
11 & 58 & 10.44 & 48 & 144 & 13 & 29 \\
12 & 59 & 10.62 & 48 & 144 & 0 & 0 \\
\hline
\end{tabular}

From the results of Table 2 it can be seen that the systems that achieve $100 \%$ annual load coverage over a typical year are those of Configurations 6 and 12. Additionally, it is observed that the system of Configuration 5 is rather acceptable since it has a very low energy deficiency of $12 \mathrm{kWh}$ or 2 hrs per year. Configuration 11 gives also a low energy deficiency of $13 \mathrm{kWh}$ but it is not considered due to its high annual period of energy deficiency which is 29 hrs per year. It should be noted that two different approaches are considered for these systems with the difference between them being that Configuration 12 has larger energy storage capacity and lower PV array power (smaller size) while Configurations 5 and 6 have larger PV array power (larger size) and lower energy storage capacity. This is a very 
important fact to consider when deciding which is the optimum configuration for the system to be designed. To do so, Configurations 5, 6 and 12 are evaluated in terms of economic viability for a total system life of 25 years. During this process the lifetime of each component is taken into consideration along with its current cost and is recorded in Table 3. The results of this analysis are presented in Table 4.

Table 3 Equipment prices used in the economic analysis

\begin{tabular}{llc}
\hline & \multicolumn{1}{c}{ Equipment Description } & Price \\
\hline 1 & Photovoltaic panels & $€ 3.2$ per W \\
2 & Batteries & $€ 640$ per pc \\
3 & Inverter (2.5 kW, 12 V) & $€ 2069$ \\
4 & Mounting system (for flat roof) & $€ 200 / \mathrm{kW}$ \\
5 & Electrical equipment (cables etc.) & $€ 210 / \mathrm{kW}$ \\
\hline
\end{tabular}

Table 4 Economic analysis results for the systems of Configurations 5, 6 and 12

\begin{tabular}{|c|c|c|c|c|c|c|}
\hline \multicolumn{7}{|c|}{ Configuration 5} \\
\hline & Equipment & Number & Power & Lifetime & Price & Price overall \\
\hline 1 & PV & 63 & 180 & 25 & $€ 36,288$ & $€ 36,288$ \\
\hline 2 & Inverter/Controller & 3 & 4500 & 15 & $€ 7,977$ & $€ 15,954$ \\
\hline 3 & Elec. Equip. & - & - & 25 & $€ 2,381$ & $€ 2,381$ \\
\hline 4 & Mounting & - & - & 25 & $€ 2,268$ & $€ 2,268$ \\
\hline 5 & Batteries & 36 & $1500 \mathrm{Ah}$ & 18 & $€ 23,040$ & $€ 46,080$ \\
\hline & & & & & TOTAL & $€ 102,971$ \\
\hline \multicolumn{7}{|c|}{ Configuration 6} \\
\hline & Equipment & Number & Power & Lifetime & Price & Price overall \\
\hline 1 & PV & 65 & 180 & 25 & $€ 37,440$ & $€ 37,440$ \\
\hline 2 & Inverter/Controller & 3 & 4500 & 15 & $€ 7,977$ & $€ 15,954$ \\
\hline 3 & Elec. Equip. & - & - & 25 & $€ 2,457$ & $€ 2,457$ \\
\hline 4 & Mounting & - & - & 25 & $€ 2,340$ & $€ 2,340$ \\
\hline 5 & Batteries & 36 & $1500 \mathrm{Ah}$ & 18 & $€ 23,040$ & $€ 46,080$ \\
\hline & & & & & TOTAL & $€ 104,271$ \\
\hline \multicolumn{7}{|c|}{ Configuration 12} \\
\hline & Equipment & Number & Power & Lifetime & Price & Price overall \\
\hline 1 & PV & 59 & 180 & 25 & $€ 33,984$ & $€ 33,984$ \\
\hline 2 & Inverter/Controller & 3 & 4500 & 15 & $€ 7,977$ & $€ 15,954$ \\
\hline 3 & Elec. Equip. & - & - & 25 & $€ 2,230$ & $€ 2,230$ \\
\hline 4 & Mounting & - & - & 25 & $€ 2,124$ & $€ 2,124$ \\
\hline 5 & Batteries & 48 & $1500 \mathrm{Ah}$ & 18 & $€ 30,720$ & $€ 61,440$ \\
\hline & & & & & TOTAL & $€ 115,732$ \\
\hline
\end{tabular}

By evaluating the results of the economic analysis it is concluded that the optimum system is Configuration 5 which consists of 63 PVs $(11.34 \mathrm{~kW})$ and 36 batteries. The cost of such a system is €102,971. It is very important to notice that in all cases examined the main part of the cost, around 50\%, concerns the batteries. Since the optimum configuration estimated has 36 batteries it is concluded that the decision for the nominal voltage of the battery bank to be at $24 \mathrm{~V}$ was correct due to the fact that if $48 \mathrm{~V}$ was chosen then the battery bank configuration 
should have been either 1 or 2 strings of 24 batteries and it is obvious that the option of 24 batteries (1 string) would be undersized and thus insufficient while the option of 48 batteries (2 strings) would be oversized with a consequent increase of the overall cost of the system.

\section{Model design for hybrid standalone PV-Wind system}

The model for the hybrid standalone PV-Wind is based on the previously developed model for the standalone PV system. The difference between the two models relies on the addition of a small domestic wind turbine (Type 90). In this system, as in all hybrid power systems, more than one source of energy is used in order to diversify the sources and achieve load coverage under various climatic conditions during the entire 24 hours period. Furthermore, it is very important to note that the operation of this system differs from that of the PV system due to the fact that the power produced by the wind turbine is directly supplied to the load through a power conditioner and the rest of the load is covered by the PV subsystem. For the design of this model two wind turbines were chosen to be considered a $1.5 \mathrm{~kW}$ and a $2 \mathrm{~kW}$. The reason for choosing these two low power domestic wind turbines is due to the fact that the wind potential in the area examined is rather low as it is illustrated in Fig. 4 where it can be seen that more than $86 \%$ of the time the wind velocity is between $0-6 \mathrm{~m} / \mathrm{s}$ and the average wind velocity is $4 \mathrm{~m} / \mathrm{s}$. The curves of power against wind velocity for the wind turbines considered are presented in Fig. 5.

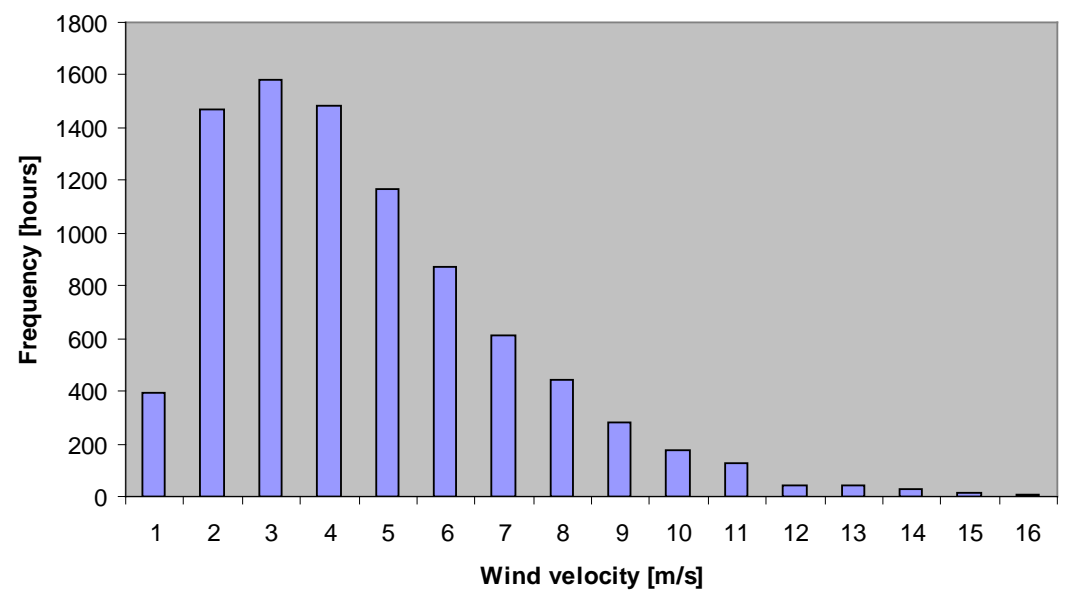

Fig.4 The wind profile of the examined location
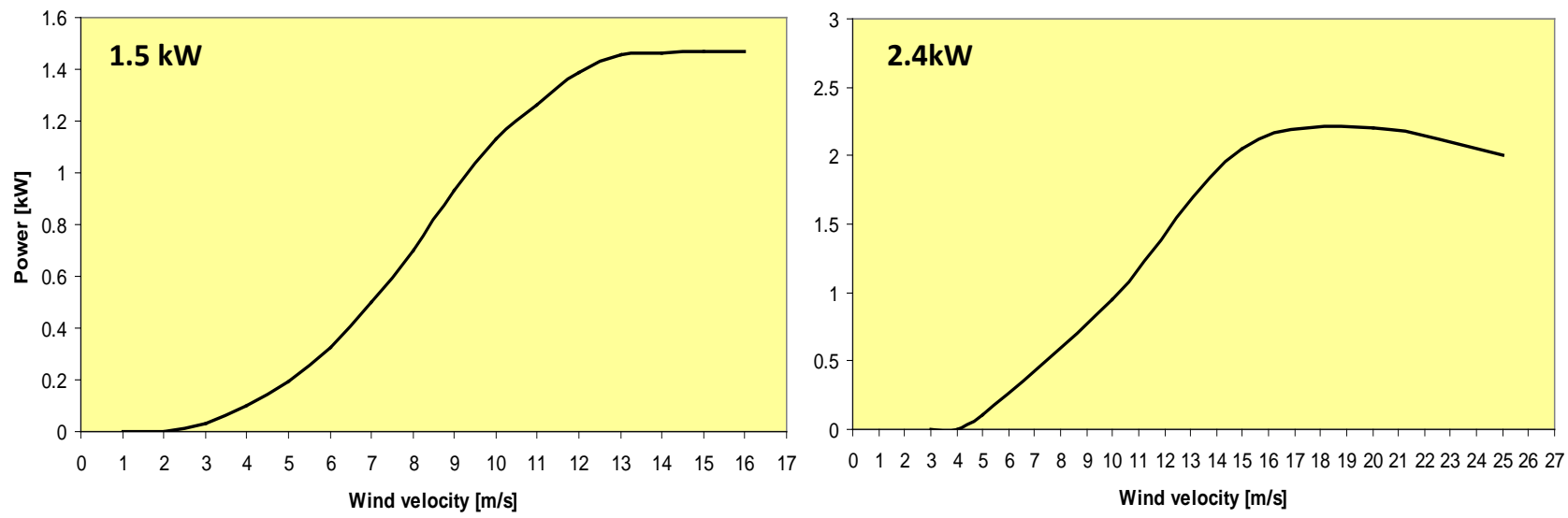

Fig. 5 Characteristic power curves for both wind turbines considered 
By carefully analyzing the power curves of each wind turbine in conjunction with the wind profile of the examined location it is hypothesized that the most suitable wind turbine to be used in the system designed is the $1.5 \mathrm{~kW}$ one. This of course is only a hypothesis and in order to be validated a series of simulations using a simple model consisting of a TMY and a wind turbine were carried out. The results obtained are presented in Table 5. From these results it is concluded that the hypothesis was correct since the $1.5 \mathrm{~kW}$ wind turbine generates more energy than the $2.4 \mathrm{~kW}$ one. This is caused by the fact that the $1.5 \mathrm{~kW}$ wind turbine operates with higher efficiency at low wind velocity which prevail at the location examined.

Table 5 Simulation results for both wind turbines examined

\begin{tabular}{ccc}
\hline Energy Produced $[\mathrm{Wh}]$ & $1.5 \mathrm{~kW}$-Wind turbine & $2.4 \mathrm{~kW}$-Wind turbine \\
\hline Maximum & 1,500 & 2,274 \\
Average & 146 & 145 \\
Annual & $1,279,346$ & $1,271,074$ \\
\hline
\end{tabular}

\subsection{Simulation and economic analysis of standalone $P V$-Wind system}

The simulation process followed for this system was similar to the one carried out for the PV system. From the results concerning the two wind turbines it is clear that the wind turbine that should be used in the system designed is that of $1.5 \mathrm{~kW}$.

Since the optimum capacity of the batteries to cover the load over a typical year was calculated during the simulation process for the PV system and found to be $108 \mathrm{kWh}$ it is decided that this capacity should also be the same for the case of the PV-Wind system as the energy provided by the wind turbine is very small.

The results of the simulation process were recorded and processed to evaluate the load coverage achieved by each configuration. The most important of the results calculated during the simulation process are presented in Table 6. From these results it can be seen that the system that achieve $100 \%$ annual load coverage over a typical year is that of Configuration $\mathrm{F}$. On the other hand the systems of Configurations B, C, D and E also gave rather acceptable results since the annual energy deficiency varied between 1-15 $\mathrm{kWh}$ while the annual period of energy deficiency varied between 7-22 hrs per year. Since all systems have the same battery capacity it is decided that the configuration to be compared with the PV system in the following section is that of Configuration $\mathrm{C}$ in order to have the same energy deficiency so as to be comparable.

Table 6 Results of the simulation process for the standalone PV-Wind system

\begin{tabular}{ccccccc}
\hline $\begin{array}{c}\text { Configura- } \\
\text { tion } \\
\text { Number }\end{array}$ & $\begin{array}{c}\text { No of } \\
\text { PVs }\end{array}$ & $\begin{array}{c}\text { PV array } \\
\text { power }\end{array}$ & $\begin{array}{c}\text { No of } \\
\text { batteries }\end{array}$ & $\begin{array}{c}\text { Battery } \\
\text { capacity }\end{array}$ & $\begin{array}{c}\text { Energy } \\
\text { deficiency }\end{array}$ & $\begin{array}{c}\text { Period of energy } \\
\text { deficiency }\end{array}$ \\
\hline A & {$[\mathrm{kW}]$} & {$[-]$} & {$[\mathrm{kWh}]$} & {$[\mathrm{kWh} / \mathrm{yr}]$} & {$[\mathrm{hrs} / \mathrm{yr}]$} \\
B & 55 & 9.90 & 36 & 108 & 24 & 33 \\
C & 57 & 10.26 & 36 & 108 & 15 & 22 \\
D & 59 & 10.44 & 36 & 108 & 11 & 7 \\
E & 60 & 10.62 & 36 & 108 & 7 & 10 \\
F & 61 & 10.80 & 36 & 108 & 1 & 10 \\
\hline
\end{tabular}




\section{Comparison and Conclusions}

The comparison is carried out for a lifetime of 25 years for both systems and the results are recorded in Table 7. From the results of the economic analysis it can be seen that the two systems have the same lifecycle cost with a slight decrease in favor of the PV-Wind system. Nevertheless, the difference in cost is very small (€1000) and it is judged to be insignificant for the cost range of the systems examined.

Table 7 Economic analysis results for PV and PV-Wind systems

\begin{tabular}{|c|c|c|c|c|c|c|}
\hline \multicolumn{7}{|c|}{ PV system } \\
\hline & Equipment & Number & Power & Lifetime & Price & Price overall \\
\hline 1 & PV & 63 & 180 & 25 & $€ 36,288$ & $€ 36,288$ \\
\hline 2 & Inverter/Controller & 3 & 4500 & 15 & $€ 7,977$ & $€ 15,954$ \\
\hline 3 & Elec. Equip. & - & - & 25 & $€ 2,381$ & $€ 2,381$ \\
\hline 4 & Mounting system & - & - & 25 & $€ 2,268$ & $€ 2,268$ \\
\hline \multirow[t]{2}{*}{5} & Batteries & 36 & $1500 \mathrm{Ah}$ & 18 & $€ 23,040$ & $€ 46,080$ \\
\hline & & & & & TOTAL & $€ 102,971$ \\
\hline \multicolumn{7}{|c|}{ PV-Wind system } \\
\hline & Equipment & Number & Power & Lifetime & Price & Price overall \\
\hline 1 & PV & 58 & 180 & 25 & $€ 33,408$ & $€ 33,408$ \\
\hline 2 & Windturbine & 1 & 1500 & 20 & $€ 2,250$ & $€ 2,250$ \\
\hline 3 & Inverter/Controller & 3 & 4500 & 15 & $€ 7,977$ & $€ 15,954$ \\
\hline 4 & Elec. Equip. & - & - & 25 & $€ 2,192$ & $€ 2,192$ \\
\hline 5 & Mounting system & - & - & 25 & $€ 2,088$ & $€ 2,088$ \\
\hline \multirow[t]{2}{*}{6} & Batteries & 36 & $1500 \mathrm{Ah}$ & 18 & $€ 23,040$ & $€ 46,080$ \\
\hline & & & & & TOTAL & $€ 101,972$ \\
\hline
\end{tabular}

From the results presented in this paper it is concluded that in spite of the fact that due to their ability to diversify the energy sources, hybrid systems are generally considered to be a better option for standalone applications, in the case of the location examined, the PV-only system is a better option. This lies on the fact that the PV system is based fully on the very high solar potential of Cyprus in contradiction to the PV-Wind system which is based on the very low wind potential observed in the area examined, which is also typical for the whole island.

It should also be noted that by not using the wind turbine in a domestic area several other possible negative aspects are avoided such as noise caused from the operation of the wind turbine, optical pollution and maintenance requirements which are not considered in the above analysis. By observing the cost analysis of both systems it can be seen that batteries represent over $50 \%$ of the overall systems' cost.

\section{References}

[1] G.P. Panayiotou, S.A. Kalogirou, G.A. Florides, C.N. Maxoulis, A.M. Papadopoulos, M. Neophytou, P. Fokaides, G. Georgiou, A. Symeou, G. Georgakis, The characteristics and the energy behaviour of the residential building stock of Cyprus in view of Directive 2002/91/EC, Energy and Buildings, 42, 2010, pp. 2083-2089.

[2] TRNSYS program manual. 